\title{
Educação para a infância na América Latina: uma perspectiva a partir da teologia da cultura
}

\author{
EIton Vinicius Sadao Tada* \\ Veronica Regina Müller**
}

\section{RESUMO}

O presente artigo discute a educação para a infância na América Latina a partir da Teologia da cultura de Paul Tillich. Para isso, o texto é dividido em três partes. Primeiramente uma apresentação da educação da infância na América Latina, em seguida faz-se uma aproximação fenomenológica a essa questão a partir do pensamento tillichiano e, por último apresenta-se uma proposição para a educação da criança na América Latina a partir de princípios tillichiano.

Palavras-chave: Infância; Criança; América Latina; Paul Tillich.

\section{EDUCATION FOR CHILDHOOD IN LATIN AMERICA: A PERSPECTIVE FROM THE THEOLOGY OF CULTURE}

\section{ABSTRACT}

The paper discuss Latin America childhood education according to Paul Tillich's Theology of Culture. The paper is divided into three parts. First, it presents Latin America's childhood education. Second, a phenomenological proximation to this subject parting from the tillichian thought is made. Then, the paper indicates a proposition to Latin America's childhood education.

Key-words: Childhood; Children, Latin America; Paul Tillich

* Teólogo. Mestre e Doutor em Ciências da Religião pela Universidade Metodista de São Paulo. Doutorando em Educação pela Universidade Estadual de Maringá.

** Licenciatura em Educação Física pela Universidade Federal de Santa Maria. Mestrado em Educação pela PUC-RS. Doutorado e pós-doutorado em História da educação Social Contemporânea pela Universidad de Barcelona. 


\section{Introdução}

Uma teologia da cultura é uma teologia que não tem sua principal preocupação voltada para a ideia de Deus, para a dogmática ou para a manutenção dos sistemas religiosos cristãos. Uma teologia da cultura está intimamente ligada com o que há de profundo na existência humana, com a substância que é revelada nos fenômenos culturais (SCHWEIKER, 138). Por isso, o objeto de estudo da teologia da cultura vai além do óbvio que poderia se revelar na sentença teologia que se aplica sobre a cultura. O objeto final do estudo da teologia da cultura é o profundo da existência humana, que dentro do sistema filosófico/ teológico tillichiano é intimamente ligado com as formas de revelação no mundo, ou seja, a profundidade da existência humana possui íntima relação com os fenômenos culturais.

Indicados os princípios que regem a teologia da cultura em geral, podemos traçar os planos do presente texto. Nele, há uma decisão elementar a ser tomada. Pode-se falar sobre as aplicações que Paul Tillich - e mesmo outros teóricos - fizeram da teologia da cultura ou pode-se aplicar a teologia da cultura aos nossos dias e aos nossos problemas específicos. Seguindo, ainda que intuitivamente, a trilha tillichiana, imaginamos que a segunda opção seja a mais pertinente para a manutenção da teoria que está completando um século. Por isso, a aplicação da teologia da cultura na perspectiva aqui adotada já é uma atualização e revisão de seus termos.

Dentre todos os usos possíveis da teologia da cultura, escolhemos aqui um que, salvo o engano, nunca foi abordado em textos sobre o pensamento de Paul Tillich - ou, em diálogo com Tillich - em língua portuguesa: a educação para a infância na América Latina.

Para tratar sobre o assunto adotamos um caminho de três passos. O primeiro é a apresentação do tema educação para a infância na América Latina, levando em conta que com o espaço disponível no presente formato de produção não poderemos ir muito além de uma formulação sumária. Em segundo lugar, abordamos o assunto como fenômeno cultural, ou seja, fazemos a leitura do fenômeno a partir da teologia da cultura de Tillich. Por último, apresentamos uma breve proposição para a educação para a infância na América Latina retomando outros pontos do pensamento tillichiano. 


\section{A educação para a infância na América Latina}

Para apresentarmos o assunto partimos de duas provocações teóricas selecionadas dentre muitas outras possíveis. A primeira é a crítica de Enrique Dussel (1980) ao Emílio de Rousseau e suas consequências para a educação moderna. A segunda é a crítica feita por Heloísa Rodrigues Fernandes (1997) ao princípio pedagógico proposto por Émile Durkheim, e também, às suas consequências para a modernidade.

Tanto a crítica de Dussel quanto a crítica de Fernandes tratam de autores modernos que deixaram suas marcas na modernidade em geral e na educação moderna em particular. No caso de Rousseau, a crítica construída por Dussel aponta que o Emílio, que é seu modelo de criança e de aluno, não possui origem nem pertença, é um órfão solto no tempo e no espaço e que deve ser moldado de acordo com os ensinamentos e interesses de seu professor. A esse menino sem pertença devem ser ensinados os princípios que garantam a ordem social, especialmente a democracia, interesse específico de Rousseau. Já no caso de Durkheim, Fernandes (1997, p.64) aponta que o autor espera que a sociedade imprima sua marca no sujeito educado, de modo que a educação seria uma guerra contra as paixões da natureza da infância. A questão é que essas "paixões" citadas e combatidas por Durkheim são exatamente características próprias da infância, como a imaginação, a curiosidade e a fantasia. Portanto, o carimbo da sociedade no sujeito criança seria justamente a vacina que o impediria de viver as características da infância, garantindo que essa criança se torne moralmente um adulto miniaturizado. A justificativa para tal proposta durkheimiana seria, mais uma vez, o bem coletivo e a ordem social.

Essas perspectivas representam bem o tipo de educação adotado na modernidade europeia, e revelam no seu bojo concepções sobre a infância nesse mesmo tempo e espaço.

Quando se trata da educação para a infância na América Latina, existem alguns pressupostos destoantes e inservíveis em relação aos conceitos supracitados. Primeiramente, a ideia europeia de infância representada pelos autores em questão, não é suficiente para explicar ou categorizar o fenômeno infância na América Latina. É difícil mensurar até que ponto essa ideia de infância recebeu respaldo social na modernidade europeia, mas é um pressuposto básico que, apesar de 
ter sido operacionalizado na realidade latino-americana, não se aplica à infância na América Latina.

A infância latino-americana não é um sujeito sem pertença. Ao contrário, ela carrega em seus traços físicos, em seu cabelo, em sua pele, as violências históricas, as dominações, e as lutas que forjaram o povo latino-americano. A face da criança latino-americana não é apenas a face do povo ameríndio que foi despojado de seu habitat e sacrificado em altares expansionistas. Há o africano em diáspora, o dominador imperialista e as diversas ondas migratórias que se sucederam em prol de uma ideia de desenvolvimento. Metaforicamente, a criança latino-americana é órfã de sua própria cultura, considerada pagã ou não civilizada e deserdada por seu pai, a violência colonizadora, cristã, machista, racista e classista.

Apesar da condição de órfã e deserdada, a criança latino-americana nada tem a ver com o Emílio de Rousseau, que era um sujeito-vácuo, sem pertença e sem conteúdo. A criança latino-americana pulsa a luta que matou seus ancestrais e expressa sua cultura na luta pelo sobreviver.

Em segundo lugar, a ideia europeia moderna de educação é, por pressuposto, inadequada para a educação na América Latina. Tanto a proposta de Rousseau quanto a proposta de Durkheim repousam sobre a ideia de uma educação voltada para a manutenção das estruturas sociais. Essa posição é compreensível - não justificável - para um continente que tem se dobrado durante séculos a um fazer científico centrado na metafísica e no método cartesiano. A suposta retidão da racionalidade hiperbólica somada aos esforços de prova e contra-prova dos filósofos empiristas sustentou com força as bases do conhecimento moderno europeu. Ainda que a educação latino-americana tenha sofrido grande influência da cultura europeia, o conhecimento na América Latina possui outras formas e outras regras.

Aqui, no ambiente latino-americano, o conhecimento não se restringe a algumas normas formais europeias. Existe, por exemplo, o conhecimento consequente das diversas ondas de resistência do povo latino-americano. Resistência a seu colonizador, aos impérios mundiais, aos novos impérios neoliberais, a diversas formas de exploração do capital, às violências neocolonizadoras, à exploração socioambiental, às ditaduras militares e não militares, entre outras. A luta e suas formas de 
resistência não são uma opção eventual para o povo latino-americano, é uma constante. Existe ainda a ciência das garrafadas, das benzedeiras, dos banhos de ervas, dos chás, da nutrição natural, da magia e da feitiçaria, de tantos axés.

Por tudo isso, não há sentido em uma educação que priorize uma estabilidade social para um povo que luta diariamente por mudanças, reformas e revoluções. Não há sentido também no desenvolvimento do produto interno bruto ou da balança comercial para países que são objetivamente lançados às margens do capital.

Assim, a educação na América Latina deveria priorizar o desenvolvimento das "paixões" que outrora foram censuradas por Durkheim. A criatividade, a fantasia, a imaginação; todos esses elementos são necessários para um povo que deseja resistir em sua luta.

A grande questão é que a gestão da educação latino-americana, por meio de governos e corporações, insiste em importar modelos educacionais do chamado primeiro mundo. Isso pode ser explicado por um lado através do sistema de financiamento educacional internacional (PERONI, 2013), e por outro na própria busca pela ideologia neoliberal. De uma forma ou de outra, a educação de modelos importados gera uma tremenda incongruência, pois seus interesses não vão ao encontro aos interesses do povo a ser educado.

\section{A educação como expressão cultural}

William Schweiker (SCHWEIKER, 2009), em seu capítulo sobre o futuro da Teologia da Cultura no Cambridge Companion sobre Paul Tillich, apresenta assertivamente um resumo sobre o que é a Teologia da Cultura e quais suas principais críticas. $\mathrm{O}$ autor apresenta a preocupação de Paul Tillich em fazer uma teologia voltada para a compreensão da revelação do conteúdo religioso nos fenômenos culturais. O religioso, nesse sentido, é a preocupação suprema da existência humana, a pergunta fundamental pelo Ser.

Paul Tillich, em sua obra Teologia da Cultura, apresenta aquilo que ele chama de uma teologia da educação. É um texto breve que explica a educação ocidental a partir de uma tripla divisão, a saber, a educação técnica, a educação humanista e a educação indutiva (TILLICH, 2010, p.197). Com essa tripla divisão Tillich dirige uma crítica específica à 
educação religiosa. Essa crítica é desenhada a partir da ideia de que o ensino religioso parte de dois problemas fundamentais. O primeiro é o fato de dar respostas a perguntas que não foram feitas por alunos. Os dogmas, o sistema teológico, os conceitos de Deus, salvação e Igreja não foram questões elaboradas pelos discentes, e mesmo assim são ensinadas. O segundo problema é o trabalho com a linguagem mítica da religião. Nesse sentido, o autor afirma que o desafio reside no fato de desmistificar o literalismo da linguagem religiosa sem perder o símbolo religioso (TILLICH, 2010, p. 205-207).

Um ponto que fica bastante evidente na proposta tillichiana de teologia da educação, é que a educação deve buscar como finalidade a abertura da mente para os mistérios supremos do Ser. Esse processo se resume a dois passos que são ligados e correlatos: a pergunta pela preocupação suprema do fundamento da existência e a elaboração de respostas a partir do uso consciente e desmistificado da linguagem religiosa e de seu poder simbólico.

Para a atualização da teologia da cultura e sua aplicação no cenário escolhido introduzimos a geração infantil em nossas reflexões. E, com foco nela, estabelecemos algumas perguntas fundamentais. A primeira delas é se a educação para a infância na América Latina proporciona a abertura da mente para os mistérios do Ser, ou seja, se com as práticas e os conteúdos da educação ofertada para as crianças na América Latina, é possível que elas façam a pergunta fundamental pelo Ser como expressão de suas preocupações supremas. Em seguida, questionamos se essa mesma educação proporciona ferramentas para que respostas possam ser dadas pelas próprias crianças a essas questões fundamentais.

Caso a resposta para essa primeira questão seja negativa, é necessário que se pergunte então qual é a expressão religiosa/cultural da educação para a infância na América Latina. Ou seja, se a expressão cultural - e a educação é uma expressão cultural - é a forma que possui um conteúdo, qual é o conteúdo específico nesse caso?

A educação sustentada pela lógica neoliberal mistura dois tipos de educação dentre os três apresentados por Tillich. Ela é técnica no sentido em que se preocupa em formar profissionais mais do que na formação de seres humanos em plena experiência existencial. Ela é indutiva na medida em que leva as crianças latino-americanas para a 
manutenção da lógica do capital, mesmo com a constante e violenta exclusão causada por esse sistema. Nesse sentido, as perguntas fundamentais apresentadas pela educação para a infância na América Latina são as perguntas sobre "o que vou ser profissionalmente quando crescer" e "como faço para alcançar a felicidade a partir do sucesso profissional e da multiplicidade do consumo". Essas questões, por vezes são respondidas com o literalismo religioso. A teologia da prosperidade ${ }^{1}$ poderia ser entendida como uma resposta nesse sentido, assim como a lógica do progresso meritocrata, o "vencer na vida a partir do esforço individual". Se essas são as questões fundamentais, é certo que a profundidade da existência não é alcançada a partir da educação entregue para as crianças latino-americanas.

Agora cabe perguntar qual o sentido da educação para a infância na América Latina como uma expressão cultural, ou seja, qual é seu fundamento. Para a Teologia da Cultura tillichiana existe uma substância religiosa que fundamenta a expressão cultural. Quando percebemos a forma como a educação para a infância na América Latina é proposta, questionamos então que tipo de fundamento religioso é esse que entrega uma educação para o mercado e não dá condições para a abertura da mente para os mistérios do Ser. É certo, do ponto de vista tillichiano, que uma educação que não se volta para a possibilidade da pergunta pela existência, pelo fundamento do Ser, é uma educação que possui um desvio de sua funcionalidade básica.

O desvio atual da funcionalidade da educação para a infância na América Latina é expressão de um desvio religioso que está na base da substância que sustenta essa educação como expressão cultural. Esse desvio, em linguagem tillichiana, é uma forma de "idolatria" que traz como consequência atitudes "demoníacas" (TILLICH, ano).

Tillich desenvolve um conceito de idolatria que é basicamente a ideia de que preocupações parciais substituem preocupações finais. Assim, a idolatria surge, por exemplo, quando o símbolo que aponta

Claudio de Oliveira Ribeiro (2007, p.56) afirma que: “A Teologia da Prosperidade está, portanto, intimamente relacionada com o sistema econômico neoliberal. Às práticas religiosas de parcela considerável da população são acopladas (ou incentivadas) práticas socioeconômicas, em consonância com a lógica do neoliberalismo. Tal aglutinação possui embasamento religioso que, indiretamente, contribui para a associação entre consumo e salvação, e entre capitalismo e Reino de Deus". 
para algo é adorado ao invés de simplesmente abrir a relação do sujeito com o simbolizado. Até a fé pode tornar-se idolatria. Aliás, como bem explana Claudio de Oliveira Ribeiro (2010), em seu livro "Pode a fé tornar-se idolatria?" essa é uma situação recorrente na religiosidade latino-americana. A solução para esse problema idolátrico é que as preocupações finais ocupem suas funções enquanto que as preocupações parciais sejam absorvidas de acordo com suas funcionalidades.

A questão do demoníaco em Paul Tillich também está ligada ao problema da confusão entre o que é parcial e o que é supremo, final. Vitor Chaves de Souza explica sobre o demoníaco em Tillich:

Esta palavra é derivada do alemão das Dämonische, que tem sua origem no grego $\delta \alpha \mu$ óviov - e que foi elaborada em inglês, the Demonic, como neologismo, pelos tradutores de Paul Tillich. O demoníaco não é um ente, mas, antes, é o desejo do ser humano e de suas ações e instituições serem últimas e supremas. Como notou Sartre, o ser humano é um ser com a ilusão de ser Deus. A reflexão de Tillich acerca da esfera do demoníaco (onde estão os imaginários de inferno/demoníaco/mal) conclui que o mal não tem poderes supremos, enquanto o demoníaco é uma possibilidade para o ser humano. O demoníaco, portanto, é tudo aquilo que na condição de finito reivindica ser último, supremo e decisivo (CHAVES, 2011, p.61).

O demoníaco é aquilo que reivindica para si as questões supremas da existência apesar de sua finitude. É nesse sentido que a educação para a infância na América Latina com perspectiva neoliberal e neocolonizadora configura uma opressão demoníaca que rouba a pertença de ser filho e possuidor de uma cultura. Ao colocar o projeto capitalista e neoliberal como objetivo final suprime-se a qualidade e a liberdade existencial, transformando assim uma ideologia finita em uma cultura demoníaca. A solução para tal problema reside no ato de colocar as questões existenciais profundas como finalidade da educação, e as ideologias finitas em seus lugares de finitude e limitação.

\section{Proposições para a educação da infância na América Latina}

Em torno da empreita de atualização da teologia da cultura, escolhemos não deixar o presente artigo no âmbito da revisão analítica, mas reservar esta terceira parte para uma proposição acerca do tema 
discutido. Como a teologia da cultura já foi usada como suporte metodológico para os tópicos anteriores não haveria a necessidade da aplicação da teoria tillichiana na proposição para a educação da infância latino-americana. Entretanto, após reflexões e discussões entre os autores do texto, decidimos que a teoria tillichiana ainda seria útil e proveitosa para a proposição que aqui se deseja fazer.

Chegou-se à conclusão de que a criança latino-americana, que tem sido educada a partir de princípios pedagógicos europeus e modernos, acaba sendo colocada na condição de órfã e deserdada. Essa criança - que possui uma pertença e uma face específica - é tirada dos braços de sua mãe cultura e deixada de lado do testamento de seu pai, o colonizador europeu e seus desdobramentos liberais e neoliberais. Por isso, dissemos acima que a forma como a educação das crianças latino-americanas tem sido conduzida configura traços de idolatria e aspectos demoníacos. Tanto a idolatria quanto o demoníaco acima explicados tratam de um desvio, de uma mudança de foco do objetivo final da educação. Portanto, a proposição para a correção desse desvio passa por um novo enquadramento dessa finalidade da educação.

Para que a educação da criança latino-americana seja adequada à sua finalidade que é, em última instância, a possibilidade da pergunta pelo Ser, propomos que a mesma seja centrada na ideia tillichiana de coragem de ser.

Tillich, em sua obra "A coragem de Ser" apresenta as características da coragem, a presença do medo e da ansiedade e, especialmente explica a coragem de ser em três partes: a coragem de ser como parte, a coragem de ser como si próprio e a coragem como transcendência. Das três categorias, as duas primeiras são as mais aplicáveis para a presente proposição.

$\mathrm{Na}$ ideia tillichiana de coragem de ser como parte o autor explica que o eu é correlato do mundo, revelando assim uma estrutura de existência relacional.

Porém, o eu é eu só porque tem um mundo, um universo estruturado, ao qual ele pertence e do qual, ao mesmo tempo, está separado. Eu e o mundo são correlatos, e assim individualização e participação. Porque isto é justamente o que participação significa: ser uma parte de alguma coisa, da qual se está, ao mesmo tempo, separado. Literalmente participação 
significa "tomar parte". E pode ser usada num triplo sentido. Pode ser usado no sentido de "compartilhar" como, por exemplo, compartilhar um quarto, ou no sentido de "ter em comum", como Platão fala de methexis (ter com), a participação do indivíduo no universo, ou pode ser usada no sentido de "ser uma parte", por exemplo, de um movimento político. Em todos estes casos participação é uma identidade parcial e uma não identidade parcial. Uma parte de um todo não é idêntica ao todo ao qual ela pertence. Mas o todo é o que é, só com a parte. A relação do corpo e seus membros é o exemplo mais óbvio. O eu é uma parte do mundo que ele tem como seu mundo. $\mathrm{O}$ mundo não seria o que é sem este eu individual (TILLICH, 1992, p.68).

De acordo com essa citação vamos separar algumas afirmações. Primeiramente o eu é dependente do mundo. O eu e o mundo são correlatos, são individualização e participação. A participação depende de uma prévia separação. Participação significa tomar parte e pode ser usada de três formas. Pode ser compartilhar, ter em comum, e ser uma parte. Nos três casos participação é uma identidade e uma não-identidade parcial.

Com essas afirmações podemos vislumbrar que a criança latino-americana precisa da coragem de ser como parte. Pela parcialidade da identidade e da não-identidade da participação, a inserção da criança em seu mundo não é suficiente para defini-la, mas é elemento constitutivo de seu eu e de seu mundo. A correlação entre individualização e participação é o elemento dinâmico central para a compreensão da criança latino-americana em seu mundo. Ao mesmo tempo em que essa criança é fruto de uma história e possui um legado de luta e resistência contra seu colonizador e contra os elementos demoníacos da colonização, ela também é um indivíduo que participa e constrói seu mundo. Portanto, a criança ao tomar parte/ participar de seu mundo - em seus três âmbitos - constrói também um mundo. Nessa dinâmica, a criança latino-americana ao tomar parte de seu mundo e da realidade que lhe é posta, resiste, e ao resistir à sua condição de órfã e deserdada, constrói uma nova realidade na qual as crianças não devem ser colocadas na condição de órfãs e deserdadas.

A condição para a efetividade do sistema de correlação entre eu e mundo é que esse tomar parte, essa participação, seja efetiva. Nesse sentido, as três formas de participação deveriam ser estruturalmente 
permitidas e incentivadas na educação para a criança latino-americana. Portanto, a criança latino-americana deveria a partir de sua educação, ter condições de ser uma porção de seu mundo, de compartilhar seu mundo e de ter um mundo em comum com outros indivíduos.

A discussão aqui feita e a proposição que está sendo desenvolvida possui um caráter ontológico próprio da natureza da discussão. Entretanto, a inserção política deve ser enfatizada como uma forma de participação da criança latino-americana em seu mundo. Essa inserção política não deveria ser um exercício metafórico de participação, mas uma participação na qual este indivíduo criança tenha seu espaço respeitado como participante do mundo.

Além da coragem de ser como parte de algo maior, como participação, Tillich também apresenta que existe uma coragem de ser como si próprio, que é a coragem de individualização do indivíduo. Tillich cita exemplos de existencialismos na filosofia, teologia, arte e literatura para explicar como se dá a coragem de ser como si próprio em seu tempo.

O homem cria o que ele é. Nada é dado a ele para determinar sua criatividade. A essência do seu ser o "deve ser", e o "tem que ser" — não é algo que ele encontre; ele o faz. O homem é o que ele faz de si próprio. E a coragem de ser como si próprio é a coragem de fazer de si próprio o que se quer ser (TILLICH, 1992, p.114).

A coragem de ser como si próprio é uma atitude existencial. Essa atitude permite que o indivíduo transcenda as ameaças a sua existência, superando a coragem do desespero. A definição tillichiana de coragem de ser como si próprio pode ser aplicada de modo a representar uma boa alternativa para a educação da criança latino-americana.

Assim como a criança latino-americana precisa participar de fato de seu mundo para executar a sua coragem de ser como parte, ela precisa fazer de si aquilo que quiser. Mas, fazer de si aquilo que quer não implica em uma ausência de educação ou de estruturas educantes. Pelo contrário, é importante que a criança tenha uma educação que lhe auxilie em suas escolhas e que ela escolha ser justamente aquilo que é.

É possível que esse ponto seja um dos mais desafiadores para uma educação da criança latino-americana. Isso se dá porque a educação moderna, conforme vimos anteriormente, tem sido justamente uma for- 
ma estrutural de transformar a criança naquilo que ela não é, ou seja, em um adulto que seja adequado para a ordem social. De semelhante modo, a criança latino-americana tem sido tratada como um objeto, e não como um sujeito de sua própria vida, de modo que sua liberdade permanece em diversos casos circunscrita ao projeto colonizador e neocolonizador. Por isso, a coragem de ser como si próprio deve ser apresentada como alternativa libertadora para a educação da criança latino-americana.

\section{Considerações finais}

A proposição feita no presente artigo é a de que a coragem de ser como parte e a coragem de ser como si próprio sejam inseridas na lógica da educação da criança latino-americana. Essa proposta pressupõe uma atitude existencial radical, ou seja, uma abertura de sentido para a vida da criança latino-americana a partir de sua educação e de seu processo educativo.

Essa proposição surge da denúncia derivada de um olhar fenomenológico para a educação da criança latino-americana em suas condições atuais, derivada de um projeto modernizador e devota a uma ideologia neoliberal. Esse olhar para o fenômeno da educação da criança latino-americana nos leva à percepção de que a educação da forma como tem sido apresentada é uma expressão cultural de qualidade demoníaca, que surge da adoção de um princípio idolátrico.

Como partimos do referencial teórico tillichiano, entendemos que a finalidade da educação é a abertura da mente para a pergunta pelo ser. Portanto, se essa finalidade não tem sido atingida - ou, pelo menos, buscada - há uma incoerência entre o que a educação tem feito e o que ela deveria fazer. Essa incoerência surge do fato de que as pessoas responsáveis pela educação buscam mais a satisfação do projeto neoliberal do que a efetivação de uma educação que permita a pergunta pelo ser.

Através da Teologia da cultura de Tillich vimos que existe uma relação estrutural entre os formatos culturais e os conteúdos religiosos. Essa relação nos permite ver quais são os conteúdos religiosos - a preocupação pelo ser, no sistema tillichiano - que se manifestam em nossa cultura. Além do âmbito da educação, a forma como a cultura lida com a infância e com a criança expressa que a criança não tem 
sido evidenciada como um ser como si próprio e não tem acessado principalmente pelo bloqueio advindo de forças externas - sua parte no ser como um todo.

Ainda, vimos que, apesar de apresentarmos essa reflexão em tom ontológico e fazermos nossa proposição na mesma linha, sabemos que a educação política - filosoficamente política, e não a simples adesão ideológica sem crítica - pode ser um dos fatores de libertação que devem ser incorporados na prática da educação da criança latino-americana.

Por fim, podemos notar que a Teologia da cultura que foi iniciada no discurso de Tillich na sociedade kantiana de Berlim há cem anos, ainda é um instrumento válido que pode ser utilizado com suas devidas adequações. Sua atualização depende das formas de aplicação que podem ser feitas hoje, através da constante relação entre adoção de uma ideia centenária e aplicação a partir de uma hermenêutica de nosso tempo.

\section{Referências}

DUSSEL, E. La pedagógica latinoamericana. Bogotá: Nueva America, 1980. FERNANDES, H. R. Infância e modernidade: doença do olhar. In.: GHIRALDELLI JR, P. Infância, escola e modernidade. São Paulo: Cortez; Curitiba: UFPR, 1997.

PERONI, V. M. V. (org) Redefinições das fronteiras entre o público e o privado: implicações para a democratização da educação. Brasília: Liber Livro, 2013.

RIBEIRO, C. de O. O que um Cristão precisa saber sobre a Teologia da Prosperidade? In: Revista Caminhando v. 12, n. 1 (2007) pp. 41 - 56. São Bernardo do Campo.

RIBEIRO, C. de O. Pode a fé tornar-se idolatria? A atualidade para a América Latina da relação entre Reino de Deus e história em Paul Tillich. Rio de Janeiro: Mauad X/ Mysterium, 2010.

SOUZA, V. C. de. "O inferno está vazio e os demônios estão aqui": uma reflexão existencialista sobre a História dos Infernos em diálogo com o demoníaco em Paul Tillich. Revista Eletrônica Correlatio v.10, n. 20 - Dezembro de 2011. São Bernardo do Campo.

TILLICH, P. A CORAGEM DE SER. Baseado nas Conferências Terry Pronunciadas na Yale University Tradução de EGLÊ MALHEIROS $5^{\text {a }}$ edição. Rio de Janeiro: Paz e Terra, 1992.

. Teologia da cultura. São Paulo: Fonte editorial, 2009. 